\title{
LECTURAS JUVENILES MEDIADAS POR LAS TIC: PANTALLAS, MUNDO DIGITAL Y TRANSMEDIALIDAD. PRESENCIAS Y PERCEPCIONES ENTRE ESTUDIANTES
}

\author{
Daniel Escandell Montiel \\ Universidad de Salamanca
}

\begin{abstract}
RESUMEN: La literatura infantil y juvenil (LIJ) ha tenido una relación más compleja de lo que se podría esperar con la transmedialidad y la intermedialidad, habida cuenta de que muchas veces se ha supuesto la predisposición casi natural de estos jóvenes lectores. En el presente artículo abordamos el peso de la cultura digital en las lecturas juveniles y qué elementos característicos pueden detectarse en este espectro creativo.
\end{abstract}

PALABRAS CLAVE: literatura infantil y juvenil, transmedia, estudiantes.

\section{MEDIATED YOUTH LITERATURE MEDIATED BY ICTS: SCREENS, DIGITAL WORLD AND TRANSMEDIALITY. PRESENCES AND PERCEPTIONS AMONG STUDENTS ${ }^{1}$}

\begin{abstract}
Both young adult and children's literature has had a more complex relationship than one could expect with transmediality and intermediality, given that the almost natural predisposition of these young readers has often been assumed. In this article we approach the weight of the digital culture in the juvenile readings and what characteristic elements can be detected in this creative spectrum.
\end{abstract}

KEYWORDS: Youth literature, transmedia storytelling, students.

Recibido: 19/05/2019

Aceptado: 16/07/2019

Correspondencia: Daniel Escandell Montiel, Universidad de Salamanca, Dpto. de Literatura Española e Hispanoamericana, Facultad de Filología. Plaza de Anaya, s/n, 37008 Salamanca. Email: danielescandell@usal.es.

1. Este artículo se enmarca en el proyecto "Intermedialidad e institución. Relaciones interartísticas: literatura, audiovisual, artes plásticas" (HAR2017-85392-P) dirigido por Fernando González García. 


\section{INTRODUCCIÓN}

El choque generacional es una parte inevitable del proceso cíclico de la sociedad con implicaciones creativas, identitarias y sociológicas que son resultado directo del empuje de los jóvenes por distinguirse y diferenciarse de la generación precedente en su necesario proceso de constitución y reafirmación (Bengtson y Achenbaum, 1993). Es igualmente inevitable que se produzca una nostalgia idealizante del tiempo pasado entre aquellos que se enfrentan al proceso de maduración, acelerado ante los impulsos del grupo más joven. Esto es algo que, además, los ambientes educativos han potenciado (Claudio, 1986) al evidenciar estos cambios y el contrato social en revisión. Resulta, por tanto, necesario trascender las limitaciones de perspectiva que supone nuestra propia conducta grupal y generacional para entender cómo se relacionan con el acto escritural y lector los más jóvenes, que empiezan a tener como algo normal el contar siempre con un teléfono inteligente, una tableta o cualquier otro de dispositivo a su lado en todo momento.

Sin embargo, es imprescindible señalar también que se produce un fenómeno paralelo al generacional- que no es sino la capacidad cegadora de las innovaciones tecnológicas y la exaltación del valor de lo nuevo por el simple hecho de ser nuevo; una suerte de tecnofilia radicalizada que tiene en su reverso la pulsión neoludita ${ }^{2}$, que cómo no ha tenido también su reflejo en el mundo de las aulas (Fuentes y Ortiz, 2004). Aunque parece admisible pensar que toda innovación tecnológica está destinada, esencialmente, a facilitarnos la vida, mejorar la calidad de la misma y desarrollar formas más eficientes y satisfactorias de llegar a un resultado (o bien de crear nuevos resultados posibles, si la innovación en cuestión es lo suficientemente disruptora), quizá el salto tecnológico en cuestión no ha madurado hasta el punto necesario o, en realidad, genera el efecto contrario o no supone cambios ni mejoras sustanciales.

Pensemos, por ejemplo, en que las pantallas táctiles llevan ya muchos años entre nosotros, pero la posibilidad de escribir y dibujar con la misma comodidad que al utilizar papel real está todavía lejos, al menos hasta donde ha llegado mi propia experiencia, puesto que la libreta y el bolígrafo siguen siendo una grandísima tecnología analógica. Eso no ha impedido su uso en contextos educativos y el análisis de las posibilidades de esta tecnología a través de tabletas y dispositivos afines incluso en edades tempranas (Couse y Chen, 2014). Lo que han señalado los estudios sobre usabilidad realizados al respecto tanto en lectura (Morris et al., 2007) como en escritura o dibujo (Siozos et al., 2008) es que, en efecto, hay una curva de aprendizaje específica para aprender a imitar los resultados que ofrece un papel o un lienzo al artista, o la celeridad del escribano, cuando no también la sutileza del trazo. El mundo digital ofrece herramientas con las que reproducir todos esos efectos, sí, y están implicadas tecnologías que han avanzado notablemente en los últimos años hasta tal punto que estamos ante ese último paso en el que se desdibujan finalmente las barreras entre la escrilectura analógica y la digital.

2. Movimiento opositor a la inteligencia artificial y, con esta, de todo avance científico vinculado, apoyado o sustentado en la informática, en ocasiones partiendo de las tesis de Theodore Kaczynski. El término fue acuñado en 2006 por Steven Jones en Against Technology: From the Luddites to Neo-luddism. 
En definitiva, todo cambio tecnológico, toda novedad que puede tener un impacto en el mundo que nos rodea se ve sometida a una lucha de tensiones entre las fuerzas y actantes sociales que se posicionan en lados opuestos de la percepción de lo que esos cambios pueden conllevar, y el ámbito educativo es uno de los moldeadores sociales más poderosos, por lo que el modo en que el contexto educativo asume estos procesos puede tener impacto a corto y largo plazo en la percepción, uso y entendimiento de dichas innovaciones técnicas. Pero, sobre todo, en el modo en que impactan en los jóvenes en formación y, a partir de ahí, en su constitución identitaria como generación.

\section{Percepciones y Prejuicios ante la juVentud (esCrilectora, o Quizás no)}

El prejuicio por edad está presente en muchos aspectos de la sociedad, como se evidencia a raíz de lo expuesto en el epígrafe anterior. Si bien uno de los focos de atención ha estado en los prejuicios hacia la tercera edad (Moreno, 2010) y cómo el ámbito educativo puede combatirlos (Cottle y Glover, 2007), no podemos olvidar la condescendencia que pueden percibir los jóvenes por parte de los adultos. Uno de los prejuicios contra este grupo es el de que no leen ni escriben, pero lo que nos indican los datos de forma clara es que en realidad se escribe y se lee más que nunca (García y Gómez, 2016). Una respuesta habitual es que ante estos datos se pase a poner en duda la calidad de lo consumido y producido.

Los términos estrictamente cuantitativos de cuánto se lee y escribe son resultado, poco discutible, del notable incremento de las comunicaciones en formato escrito a través de chats, sistemas de mensajería y demás mecanismos de la red social y las aplicaciones que usamos en nuestros teléfonos, tabletas y ordenadores, con múltiples consecuencias pragmáticas, ortográficas, etc. (Yus, 2001). Así pues, se trata de un uso instrumental del lenguaje orientado a establecer comunicaciones satisfactorias entre individuos o colectivos, por lo que los parámetros cualitativos (literarios) son difícilmente definibles más allá del enjuiciamiento derivado de la ortografía y gramática empleadas en la creación de esos mensajes más allá de si logran o no su objetivo comunicativo.

El prejuicio se basa, al menos en parte, en que el hábito de tener entre las manos un libro ha dado paso claramente a tener en las manos un dispositivo móvil. Esta costumbre se ha expandido hasta el uso multipantalla, es decir, hasta la costumbre creciente de usar nuevos dispositivos para estar conectados mientras, por ejemplo, vemos un programa de televisión (Gómez et al., 2016). Por tanto, no se trata ya de estar ante una pantalla o cuál de todas las que tenemos en nuestro entorno capta nuestra atención o qué uso se le da, esto es, si el tiempo de ocio es conquistado por el televisor, el ordenador o el móvil y, dadas las capacidades multimedia de todos ellos, si estamos conectado a internet, jugando con videojuegos o consumiendo algún tipo de contenido audiovisual pasivo. Por supuesto, en el ambiente laboralescolar hay una lucha similar: la mayor capacidad técnica y versatilidad de móviles y tabletas permite que se puedan usar con fines educativos y cuentan, además, con un catálogo creciente de software típicamente profesional para los ambientes de oficina. 
Según los datos hechos públicos para el año 2014 a través del informe del Instituto Nacional de Estadística indicaba que en aproximadamente el $77 \%$ de los hogares españoles con niños estos usaban tabletas. Este dato se ve reforzado por el hecho de que los datos globales muestran que sigue habiendo un evidente crecimiento en el uso y propiedad de tabletas y dispositivos afines entre los niños. Estos datos, por sí mismos, solo nos permiten constatar que los dispositivos móviles se han convertido en uno de los elementos de ocio electrónico preferidos por los jóvenes usuarios y especular sobre un uso multipantalla y simultáneo junto a otros dispositivos y formas de entretenimiento como se ha detectado ya en adultos. En 2017 los datos indicaban ya un uso extendido del ordenador $(92,4 \%)$ en la población infantil de 10 a 15 años y un acceso a internet del 95,1\%: en 2016 el acceso a internet superaba por primera vez el acceso al ordenador gracias a la penetración de móviles y tabletas. Se evidencia, de este modo, cómo se produce un último aceleramiento en los años recientes, si bien una vez se supera la barrera del 90\% el progreso es más lento. En todo caso, podemos hablar de un alcance prácticamente total, en territorio español, de estas tecnologías para el grupo poblacional de 10 a 15 años, con resultados similares en las posteriores etapas educativas.

Entre las razones por las que tabletas y otros dispositivos han funcionado tan bien entre el público infantil está su mayor facilidad de uso por su interfaz táctil e intuitiva a partir de los cánones estéticos y de uso que Apple impuso con el debut de su iPhone (fue presentado el 9 de enero de 2007 y su uso y diseño se trasladó directamente al iPad), imponiéndose así a las interfaces de las PDA precedentes y a los conceptos de tableta como traslación directa del escritorio de los sistemas operativos de ordenador. La eclosión del mercado, con la proliferación de modelos en un amplio rango de precios, tamaños y características técnicas, gracias al carácter abierto de Android (frente al ecosistema cerrado tradicional de Apple), ha sido otro factor importante para situar este tipo de dispositivos por encima de los ordenadores. Si añadimos su capacidad multimedia, amplio catálogo de aplicaciones de productividad y la apuesta por el entretenimiento (videojuegos, vídeo bajo demanda, música, libros, etc.), con un mercado de software con precios a la baja o incluso centrado en la publicidad o las suscripciones, nos encontramos ante una categoría de producto con muchos atractivos que se suma como pantalla secundaria o principal a un mundo ya de por sí hiperconectado y mediado por dispositivos electrónicos. Para el público juvenil y adolescente hay que sumar, por supuesto, la proliferación de redes sociales, que incluso han abandonado ya el ordenador como eje principal de su acción para hacer de tabletas y móviles su plataforma esencial y aprovechar sus cámaras, conexión a internet y demás características técnicas para permitir a los usuarios compartir de forma inmediata la cotidianidad.

\section{Literatura más ALLÁ DEL libro tradicional: EL HECHO LITERARIO EN EL MUNDO DE LA DIGITALIDAD}

La creatividad literaria orientada al público juvenil ha apostado por la integración de componentes intermediales o transmediáticos, muchas veces por la integración directa de los aspectos inherentes al mundo digital a través de la producción de textos (interactivos en diferente grado) para dispositivos electrónicos. 
Desde un punto de vista estrictamente teórico a la hora de abordar la transmedialidad, debemos prestar atención a la conceptualización de este término y sus implicaciones mediales. No en vano, estamos ante uno de los aspectos todavía no resueltos a la hora de abordar la relación entre diferentes medios para construir obras complejas que lleven al receptor de un tipo de soporte a otro (esto es, saltar de un medio a otro para dar lugar a una obra completa que, de lo contrario resultaría fragmentaria, incompleta e inconsistente). La problemática surge del hecho de que, terminológicamente, se han empleado sin matices y cruzando significados términos importantes con cargas significantes y tradiciones de estudio bien diferentes.

Por eso resulta imprescindible recordar la clarísima definición que aporta Long para distinguir entre intermedialidad (esto es, adaptación) y transmedialidad: "ReteIling a story in a different media type is adaptation, while using multiple media types to craft a single story is a transmediation" (Long, 2007, p. 22). La definición de Long nace directamente de aplicar el criterio fundamental de no repetición que enunciaba Jenkins ya en 2003 para hablar de transmedia storytelling: si se repite la historia, ya no es transmedia, sería una adaptación, o en su terminología un salto mediático intermedial (o cross-media).

Si la no-repetición es clave para hablar de una transmedialidad plena, entonces es necesario asumir que en la mayoría de los casos las obras transmedia deben responder a un plan previo (Gonçalves, 2012, p. 24): ya desde la conceptualización de la obra compleja y multimedial estos saltos de un plano a otro deben formar parte de un esquema narrativo superior. Es más: los diferentes fragmentos de los múltiples medios deben ser canónicos, lo que ayuda a cumplir con los requisitos de homogeneidad, coherencia y canon (Long, 2007, pp. 34-40; Llosa, 2013, pp. 47-49). Teniendo todo esto en consideración se entiende que ya señaláramos en el pasado que "el dispositivo enunciativo transmediático satisfactorio es aquel que construye en su conjunto global un universo ficcional de múltiples medios, un corpus múltiple y complejo que se expande en varios soportes semióticos" (Escandell, 2015, p. 263).

En el espacio de la creación digital, desde el punto de vista de lo literario (en este sentido, cuando el componente escritural se sitúa en un centro más o menos difuso según la distribución de pesos transmediática), la transmedialidad es mucho más factible que al recurrir al formato impreso tradicional o libresco. Esto se debe a una simple cuestión práctica, pero también se apoya en un componente estructural. Por un lado, es mucho más fácil para el receptor saltar de un medio a otro si está accediendo al núcleo de la obra a través de un dispositivo con capacidades multimedia, como un ordenador, una tableta o su móvil. Una obra literaria digital conlleva estar empleando ya uno de esos dispositivos (o cualquier dispositivo afín), por lo que la exigencia al receptor es menor que si le pidiéramos leer un libro, e ir al cine, y ver una serie, etc. Estructuralmente, es innegable que la literatura digital ha estado tradicionalmente ligada a una tradición rupturista e innovadora, por lo que buscar las fronteras del texto y explorar sus relaciones con otros formatos y medios ha sido un paso natural dentro de esta forma de creación.

En el contexto del espacio digital las obras artísticas no solo se trasladan a un entorno de virtualidad sustentada en código binario y pantallas, sino que este cam- 
bio de paradigma implica también una alteración que resulta en muchas ocasiones elemental para la relación que se establece entre autor, obra y receptor: la capacidad de este último para interaccionar con la creación.

En el contexto del consumo medial de la multipantalla y el libro como espacio híbrido se ha experimentado con la integración de códigos QR que pueden ser leídos por los móviles y cargar contenidos multimedia en el dispositivo o presentar elementos de realidad aumentada. Un ejemplo ya clásico de este planteamiento lo tenemos en el libro De Alaska a la Patagonia en elefante (Ocón y Escalera, 2016), de la editorial LibrosQR, o la novela La leyenda del ladrón, publicada por Planeta y firmada por Juan Gómez-Jurado en 2012. En este caso, debemos señalar que incluso el libro en formato electrónico recurre a los mismos códigos que la versión impresa en vez de apostar por la integración de los contenidos multimedia, pues se concibe como un émulo sin más del soporte físico tradicional sin pretender en ningún momento aprovechar las posibilidades expansivas de la tecnología sobre la que opera. Por su parte, Sony experimentó con libros interactivos en realidad aumentada a través de la tecnología PlayStation Eye y el Wonderbook con títulos como Diggs Detective Privado, desarrollado por Moonbot Studios y lanzado en 2013, o el célebre Book of Spells (SCE London Studio, 2012), ambientado en el universo de Harry Potter y que sirvió como debut de esta gama de productos en las que el libro físico es parte de la experiencia combinada con la consola, sus periféricos y el televisor, pantalla donde se ejecuta en última instancia la acción. Se trata, cuando menos, de una versión digital, interactiva y expandida del libro de pop-up partiendo de un soporte o medio físico que se transforma en digital en la pantalla a través de la realidad aumentada.

Así pues, en el ámbito estricto de lo libresco y la lectura en los dispositivos tecnológicos actuales, los receptores se pueden ver también inmersos en un sistema multipantalla o en usos quizá todavía inesperados de las tecnologías implicadas, como la realidad aumentada. En algunos casos se desdibuja la frontera entre lo lector y la recepción activa o pasiva de contenidos multimedia, situando al libro y el acto de lectura en un papel secundario y complementario para una actividad lúdica diferente, sí, pero la fuerza icónica del libro como objeto sigue presente y se integra en estas nuevas formas.

En el caso de los videolibros o libros-app se da también una reducción de posibilidades del uso multipantalla. Se trata de aplicaciones interactivas que combinan elementos narrativos basados principalmente en la recepción de audio solo o vídeo que pueden ir desde la recepción pasiva total (heredera de los audiolibros) o bien con cierto grado de interacción en momentos concretos. Este tipo de productos ha trascendido definitivamente el nicho que antes se les atribuía de estar pensados para personas con discapacidad visual o auditiva -según formato-, en buena medida por la proliferación de propuestas diferentes en la web y en dispositivos interactivos. Asimismo, debemos tener en consideración que en esta categoría entrarían también las hibridaciones que por su grado de interactividad se situarían a medio camino entre la lectura y el videojuego, según el peso del componente textual, empezando ya en las clásicas aventuras textuales para ordenador y llegando hasta exponentes actuales como Device 6 (Simogo, 2013). 
Como en el sector más adulto o joven-adulto, el público infantil y juvenil ha tenido su buena dosis de obras que han apostado por la transmedialidad para construir mundos complejos en los que la lectura es, en sentido estricto, solo una parte de la experiencia. Lo transmedia -como exponíamos previamente- implica combinar diferentes espacios y medios narrativos (como, por ejemplo, libros, videojuegos y cine) de manera que la narración está en cierto modo fragmentada. Así, el receptor debe transitar múltiples caminos para conocer la totalidad del mundo creado: la vinculación entre las partes, situadas en diferentes medios narrativos, construye una unidad superior. Existe, por tanto, la posibilidad de una recepción multipantalla nuevamente: la del libro -en función de dónde y cómo se lea, claro-, la del cine o televisor (como sujetos pasivos) y la de las múltiples interacciones posibles a través de los videojuegos.

\section{LAS POSIBILIDADES CREATIVAS DEL JOVEN ESCRITOR Y EL UNIVERSO FANDOM}

El público juvenil ha recibido muy bien este tipo de producto, a veces asociado con las adaptaciones al cine de los fenómenos literarios del momento (las sagas Harry Potter, Twilight o Divergent, por nombrar ejemplos recientes). Estas adaptaciones suponen por lo general un salto de un medio a otro, es decir, adaptación a otro tipo de formato narrativo y no son experiencias transmedia como, por ejemplo, la construida con la saga The Matrix a través de su trilogía de películas, videojuegos y cómics. Sea como fuere, debemos aceptar que el éxito de las producciones cinematográficas supone un posterior impulso para los libros que han generado este universo y creado una primera esfera de reconocimiento a través de sus comunidades de admiradores y aficionados quienes, a su vez, han encontrado en las posibilidades de la Web 2.0 una vía de difusión absoluta para sus ficciones-fan, es decir, todas las historias alternativas que los aficionados crean a raíz de su admiración por la obra original.

Aunque es cierto que las literarias son dominantes, existen también cómics, películas, videojuegos, etc., que producen los fans como tributo a las obras originales y como vía de dar salida a su propia creatividad. Al mismo tiempo, tienen notable difusión -siempre fuera de los canales comerciales- entre las comunidades de aficionados, quienes consumen estas historias alternativas, avivando la pulsión creadora de los otros y fomentando en muchas ocasiones el debate en los espacios de la red social. A su vez, las creaciones se dividen en múltiples subgéneros que incluyen también géneros a priori no recomendados para jóvenes receptores que son fruto de la producción de adolescentes o adultos que se han visto sumergidos también la comunidad fandom. Estos escritores y creadores aficionados se reúnen -virtualmente- en comunidades en línea y en espacios de la red pensados específicamente para poder compartir textos, como las célebres Wattpad o FanFiction. Esta última tiene más de 650000 historias inspiradas en el mundo Harry Potter y alberga también cientos de miles de historias creadas por aficionados que se basan en todo tipo de cómics, películas, videojuegos, juguetes, grupos musicales, libros, etc., que han conseguido generar una pulsión escritural en sus receptores.

Que las historias creadas por aficionados sean predominantemente escritas, con independencia de si toman como punto de partida libros, películas o cualquier otro 
elemento (narrativo o no), nos indica que hay una conciencia de la capacidad y potencia de la escritura creativa. Por supuesto, hay otros factores externos, como la inmediatez de la escritura y su coste (virtualmente nulo) y baja complejidad técnica frente a, por ejemplo, crear un cortometraje o un videojuego, o incluso dibujar un cómic, por citar algunos ejemplos.

Como jóvenes creadores no cuentan, en líneas generales, ni con las destrezas ni con los recursos económicos necesarios para crear historias en formatos complejos como la transmedialidad o perseguir la interacción propia de un videojuego. Por supuesto, hay notables excepciones que se publican, normalmente tras meses (o incluso años) de dedicación y esfuerzo, pero prototípicamente se generan en grupos de aficionados que ya pueden considerarse alejados del receptor juvenil.

Lo que no podemos obviar es que algunas de las comunidades fandom más grandes se han generado a partir de obras literarias para público infantil-juvenil publicadas en formato absolutamente tradicional. Ya hemos señalado antes que las adaptaciones al cine y otros medios suponen un importante revulsivo para su popularidad, pero eso es algo que puede hacernos perder la perspectiva fundamental de que, para empezar, si han llegado al cine es porque ya había detrás una fuerte comunidad lectora. Asimismo, el posterior éxito de películas, series de televisión, videojuegos, etc., retroalimenta a las producciones literarias.

Esta esfera de creatividad dentro de la fan-fiction es posible gracias no solo a los niveles de alfabetismo tradicional de los jóvenes receptores, sino también a su desarrollo personas competentes en los nuevos alfabetismos de la esfera digital. Lankshear y Knobel (2003) ya identificaron esta confluencia de factores, esencialmente formativos, pero debemos tener en consideración otros componentes también relevantes en el fenómeno como la fuerte relación afectiva que los receptores juveniles establecen con estos personajes fictivos y cómo esta se refuerza significativamente a través de la apropiación de los personajes para crear nuevas historias en universos y con personajes ya familiares. Este es, poca duda cabe, el motor principal que impulsa el fenómeno y finalmente retroalimenta el consumo literario, aunque la capacitación técnica y dominio de las destrezas implicadas para escribir y publicar en la red son necesarias para poder llevar esos textos a las comunidades de aficionados.

Consideramos que es fácilmente observable una diferencia entre qué tipo de lecturas y tecnologías asociadas a la misma realizan los jóvenes y cómo reproducen ellos después el acto creativo. Las motivaciones que provocan esta oposición entre una acción y otra han sido el foco de una serie de breves cuestionarios que pasar a un pequeño grupo de escrilectores juveniles (tres chicas y tres chicos españoles de quince a diecisiete años en el momento de dichas entrevistas, esto es, 2016) ${ }^{3}$ localizados a través de su participación en comunidades de escritores aficionados.

3. Si bien resulta obvio que la muestra es limitada, consideramos que tiene un valor cualitativo que permite trazar algunas observaciones válidas sobre las percepciones creativas en el mundo digital de escrilectores adolescentes que se dedican de forma activa al hecho literario con interés en la difusión de sus textos aprovechando las herramientas digitales. El perfil es, por tanto, restrictivo, pero de elevado interés para el análisis que se propone en estas páginas. 
Tal y como esperábamos, todos ellos declararon poseer teléfono móvil inteligente con acceso a internet, ser usuarios habituales de distintas redes sociales, usuarios de videojuegos y contar con más dispositivos tecnológicos en su casa (como ordenador, consola, etc.). Por su pulsión escritora podemos asumir que son lectores habituales, algo que luego se corroboró en el cuestionario. Por otro lado, su inmersión en las TIC es percibida como algo normal y salvo excepción todos ellos indicaron que su círculo de amistades posee más o menos el mismo acceso a este tipo de dispositivos. Estamos, por tanto, ante un grupo de jóvenes adolescentes en entornos familiares con los recursos económicos necesarios para cubrir los costes asociados a la sociedad 2.0: recordemos que la tecnología sigue implicando un umbral de gastos que imposibilita su democratización real en todos los niveles de la sociedad.

En este grupo de muestra todos afirmaron ser usuarios activos de varias redes sociales (Snapchat, Twitter, etc.), por lo general con múltiples accesos diarios, así como de sistemas de mensajería (en especial WhatsApp). Sin embargo, no ven estas redes como espacios de lectura o creación, pese a que múltiples estudios han mostrado el potencial creativo de las mismas y las formas literarias surgidas en ellas (blogoficciones, tuiteratura, etc.). Se trata de sistemas de comunicación que no explotan creativamente ni son tampoco seguidores de autores que las empleen para publicar textos (sí siguen las cuentas oficiales de escritores reconocidos, pero el uso de sus perfiles se orienta más bien a la publicidad de sus libros).

Varios de estos jóvenes han tenido un blog, pero en la mayoría de los casos lo han abandonado un tiempo después para favorecer la comunicación en redes sociales, donde consideran que hay una mejor gestión de a quiénes llegan y obtienen también un feedback. De hecho, solo uno de ellos mantiene en estos momentos un blog, en el que escribe esporádicamente textos de distinta extensión, aunque con un carácter fundamentalmente autobiográfico o reflexivo más que creativo.

Su espacio preferido para escribir son las webs tipo Wattpad y los textos son, generalmente, de carácter atomista e independiente, con solo ocasional tendencia a la estructura episódica o la escritura de textos de cierta extensión. La preferencia hacia el texto independiente y relativamente corto parece responder al deseo de publicación rápida y a las ventajas de la concreción, pese a que entre sus lecturas de referencia ninguno de ellos ha mencionado obras de este tipo: predominan por completo las novelas con solo algunas pocas referencias a obras poéticas, con una nómina heterogénea que incluye clásicos literarios y obras contemporáneas para público juvenil. Por tanto, leen mayoritariamente novelas, pero escriben textos de corta extensión, algo que atribuimos a la complejidad y dedicación de los textos largos y a la percepción de que el relato corto es un género más apropiado para la red y la lectura en pantalla.

Entre los hábitos de lectura, debemos destacar que responden preferencialmente al perfil de un lector de formato impreso. Es decir, tienen los libros en formato físico y la lectura en formatos digitales es secundaria: leen otras creaciones de aficionados, blogs, revistas en línea, etc., pero no son compradores ni lectores de libros digitales ni afines. Conocen obras y formatos digitales que permiten expandir el concepto de libro, como algunos de los ejemplos que hemos expuesto en epígrafes 
anteriores, pero o los asocian con literatura concebida para un público infantil o bien los categorizan como videojuegos u otro tipo de experiencias narrativas fuera del canon de la lectura.

Además de fan-fiction, prácticamente todos ellos admiten escribir textos en los que no hay apropiación de personajes o universos preexistentes, aunque en la inmensa mayoría de los casos no los han publicado en la red. En cuanto a las motivaciones que los llevan a escribir fan-fiction destaca el deseo de formar parte de una comunidad, ganar relevancia en la misma y establecer un vínculo con los demás (por encima de vinculaciones emocionales con la propia obra); de hecho, entre las razones para publicar en comunidades y no en blogs u otros espacios está el recibir feedback de la comunidad. Entre los puntos negativos señalados de este formato destaca el temor a los trols (así como otras actitudes agresivas y tóxicas dentro de las comunidades en línea) y las críticas negativas. En esta misma línea, algunos reconocen leer y comentar textos de otros buscando una reciprocidad, es decir, para ser leídos y recibir también alabanzas.

Entre los encuestados, ninguno ha intentado crear videojuegos, cortometrajes $u$ otro tipo de producciones similares, aunque sí reconocen haber imaginado cómo harían ellos una entrega de alguna de sus sagas preferidas. En este sentido, se evidencia que la facilidad para escribir y publicar en línea, sumado al aparente desconocimiento de herramientas de producción amateur en otros medios, es una ventaja inherente a la escritura frente a otras formas de creación narrativa. No les falta motivación ni imaginación para pensar en cómo harían su videojuego o película, pero sí las herramientas y quizá el tiempo, además de percibir que la satisfacción de ofrecer estas obras al público se demoraría (al igual que si escribieran una novela) frente a la inmediatez de colgar en la red sus relatos.

Por último, todos ellos han indicado que comentan a través de las redes sociales sus experiencias vitales y también parte de su ocio, como los programas de televisión que siguen. En esa misma línea, la mitad ha dicho que siguen a youtubers que ofrecen contenidos que combinan el vlog y la emisión de partidas de videojuegos que comentan sobre la marcha, compartiendo así la propia experiencia. Por tanto, el ocio y el propio acto de compartirlo con la comunidad, resulta normal para ellos y les sitúa también en el conjunto de receptores multipantalla, capaces de dividir con éxito su atención entre lo que siguen y la conversación en marcha en las redes sociales que se genera en torno a esa pieza de entretenimiento. Y eso es, en este momento de sus vidas, lo más interesante: tan solo uno confiesa tener como meta profesional ser escritor, mientras que los demás ven esta actividad como un entretenimiento. Ocio escritural, sin más complicaciones ni diferencias sustanciales con cómo perciben otras maneras de pasar su tiempo.

\section{Conclusiones}

En el pasado hemos propuesto el uso de la literatura digital como herramienta educativa por su intrínseca capacidad para potenciar no solo las destrezas de la escrilectura, sino también por su potencial también nativo de promover la educación y 
alfabetización digitales, aunque desde un punto de vista estrictamente centrado en la recepción. La percepción de los jóvenes escrilectores parece sugerir que el desarrollo creativo es también apropiado para potenciar todas las destrezas relevantes en contextos digitales, pero, más que eso, algo necesario: su orientación creativa de corte más conservador y centrado en el texto frente a la fusión mediática sugiere que puede ser necesario cultivar desde contextos educativos las destrezas creativas con un perfil más integrador que les dé los recursos necesarios para expresarse creativamente en el contexto de la transmedialidad.

Para llegar a ese paso consideramos necesario explotar los acercamientos a la transmedialidad, digitalidad y narrativa de videojuegos que se ha hecho desde géneros relevantes para la literatura infantil y juvenil, como los expuestos en las páginas precedentes. Estas obras pueden constituir un corpus de ejemplos relevantes que sirvan como modelo de exploración transmedia para los jóvenes escrilectores. Un primer paso necesario para la estimulación creativa es el acercamiento a modelos, tal y como hacemos con la literatura tradicional y la introducción de modelos literarios canónicos.

Puesto que existe ya una ubicuidad suficiente de la tecnología precisa, y los jóvenes escrilectores están más que familiarizados con este tipo de prácticas, solo podemos asumir que si no crean en dichos formatos complejos es, ante todo, porque asumen que no son capaces o porque sienten que no tienen las herramientas apropiadas para ello. El contexto educativo es el espacio apropiado para cubrir este tipo de destrezas con las herramientas de diseño y producción que pueden introducir herramientas de alfabetización mediática más allá del papel de receptor para potenciar las capacidades comunicativas en un mundo de narrativización compleja como el que se dibuja en el horizonte de la conceptualización creativa que lleva ya varios años entre nosotros.

\section{REFERENCIAS BIBLIOGRÁFICAS}

Bengtson, V. L. y Achenbaum, W. A. (eds.) (1993). The changing contract across generations. Nueva York: De Gruyter.

Claudio Puerto, A. (1986). El fenómeno social de la educación como fundamento de las diferencias generacionales. Educar, 9, 35-41.

Cottle, N. R. y Glover, R. J. (2002). Combating Ageism: Change in Student Knowledge and Attitudes Regarding Aging. Educational Gerontology, 33(6), 501-512. https:// doi.org/10.1080/03601270701328318.

Couse, L.J. y Chen, D.W. (2014). A Tablet Computer for Young Children? Exploring its Viability for Early Childhood Education. Journal of Research on Technology in Education, 43(1), 75-96. https://doi.org/10.1080/15391523.2010.10782562.

Escandell Montiel, D. (2015). La construcción transmedia y sus fronteras entre cómic y videojuego. La industria española frente a la estadounidense. En A. Florenchie y D. Breton (Eds.), Nuevos dispositivos en la era intermedial (pp. 253-280). Lyon: Orbis Tertius. 
Fuentes Esparrell, J. A. y Ortiz Gómez, M. M. (2004). Una aproximación a la antinomia tecnofobia versus tecnofilia docente. Publicaciones, 34, 37-42.

García Rodríguez, A. y Gómez Díaz, R. (2016). Lectura digital infantil. Dispositivos, aplicaciones y contenidos. Barcelona: UOC.

Gómez Díaz, R., García Rodríguez, A., Cordón García, J.A. y Alonso Arévalo, J. (2016). Leyendo entre pantallas. Gijón: Trea.

Gómez Jurado, J. (2012). La leyenda del ladrón. Barcelona: Planeta.

Gonçalves Moraes, E. (2012). De narratividade à narrativa transmídia: a evoluçao do processo comunicacional. En C. Campalans et al. (Eds.), Narrativas Transmedia: entre teoría y práctica (pp. 15-25). Bogotá: Universidad del Rosario.

Instituto Nacional de Estadística (2017). Encuesta sobre Equipamiento y Uso de Tecnologías de Información y Comunicación en los Hogares. Año 2017. INE. Recuperado de https://www.ine.es/prensa/tich_2017.pdf.

Instituto Nacional de Estadística (2017). Encuesta sobre Equipamiento y Uso de Tecnologías de Información y Comunicación en los Hogares. Año 2014. INE. Recuperado de https://www.ine.es/prensa/np864.pdf.

Jenkins, H. (2003). Transmedia Storytelling. MIT Technology Review. Recuperado de https://www.technologyreview.com/s/401760/transmedia-storytelling.

Jones, S. (2006). Againts Technology: From the Luddites to Neo-luddism. Nueva York: Routledge.

Lankshear, C. y Michele, K. (2003). Nuevos alfabetismos. Su práctica cotidiana y el aprendizaje en el aula. Madrid: Morata.

Llosa Sanz, A. (2013). Más allá del papel. El hilo digital de la ficción impresa. Vigo: Academia del Hispanismo.

Long, G. A. (2007). Transmedia Storytelling. Business, Aesthetics and Production at the Jim Henson Company (tesis doctoral). Massachusetts Institute of Technology.

Moonbot Studios (2013). Diggs Detective Privado [PlayStation 3]. Shreveport: Sony Computer Entertainment.

Moreno Toledo, A. (2010). Viejismo (ageism). Percepciones de la población acerca de la tercera edad: estereotipos, actitudes e implicaciones sociales. Poiésis, 19, 1-10. https://doi.org/10.21501/16920945.101.

Morris, M. R., Bernheim Brush, A. J. y Meyers, B. R. (2007). Reading Revisited: Evaluating the Usability of Digital Surfaces for Active Reading Tasks. IEEE Xplore. https://doi.org/10.1109/TABLETOP.2007.12.

Ocón, R. y Escalera, N. (2016). De Alaska a la Patagonia en elefante. Madrid: LibrosQR.

SCE London Studio (2012). Book of Spells [PlayStation 3]. Londres: Sony Computer Entertainment. 
Simogo (2013). Device 6 [iOS]. Malmoe: Simogo.

Siozos, P., Palaigeorgiou, G., Triantafyllakos, G. y Despotakis, F. (2008). Typing Versus "Digital Inking": Computerized Handwritten Testing on the Tablet PC. En J. Luca y E. Weippl (Eds.), Proceedings of ED-MEDIA 2008--World Conference on Educational Multimedia, Hypermedia \& Telecommunications (pp. 5413-5421). Viena: Association for the Advancement of Computing in Education (AACE). Recuperado de https://www.learntechlib.org/primary/p/29127/.

Yus, F. (2001). Ciberpragmática. El uso del lenguaje en Internet. Barcelona: Ariel. 